\title{
CUANDO LOS CONTENIDOS DE LA ESCUELA TRADICIONAL... NO PASAN EL TÚNEL
}

Tomás Surhoff; Marcela Valdés; Gustavo González; Jeanette Orellana

Fundación Mis Pasos, Chile. Fono: +56 32 2973477. Correo electrónico:

educacion@fundacionmispasos.cl

Estimado Sr. Editor:

A mediados del mes de noviembre tuvimos la oportunidad de realizar una salida con los niños de la Escuela Pikler perteneciente a la Fundación Mis Pasos, al Túnel de la Ciencia en Valparaíso. Era una oportunidad interesante para observar de qué manera se relacionaban ellos en un contexto distinto al que experimentan cotidianamente. Las visitas al "Túnel" son organizadas siempre de la misma manera: los grupos son recibidos por uno de los encargados, quien les asignaba un monitor que los guiaba a través de los distintos módulos, explicando y preguntando. Al final, éste se despedía, invitándolos a recorrer la exposición libremente

Durante la exposición con los niños de nuestra Escuela (grupo heterogéneo, niños de 3 a 10 años); pudimos observar que ellos poseen conocimientos y saberes, los llamados "contenidos" por la escuela tradicional, (aquellos conocimientos que se espera que los niños sepan según su edad y nivel). Interactuaron con el monitor de forma espontánea y activa, seguros de ellos mismos, respondiendo a sus preguntas, haciendo observaciones interesadas acerca de lo explicado. Aun cuando el monitor estructuraba sus presentaciones de forma magistral siguiendo la lógica escolar, los niños siempre lo interpelaron, pero no de forma desafiante o irrespetuosa, al parecer, al estar ellos acostumbrados a relacionarse con los adultos de manera transversal y segura en su contexto diario, les posibilitó expresarse libremente cuando conocían algo o cuando algo les llamaba la atención. Una vez terminado el recorrido fueron invitados a moverse libremente, ocasión que ellos aprovecharon con entusiasmo para volver a aquello que más llamó su atención, descubriendo nuevas cosas, que alegres y apasionados compartieron con los demás (adultos y niños). Los niños se movieron confiados y los adultos se mantuvieron cercanos, 
disponibles y asombrados ante sus hallazgos. Poco a poco se congregaron y fueron coincidiendo en un mismo lugar, al preguntarles si estaban listos, exclamaron que sí, se despidieron amablemente, dando las gracias a los encargados.

Esta salida nos hizo reflexionar como Equipo y nos preguntamos acerca de las otras realidades que viven niños que estudian en colegios y escuelas tradicionales, ¿Cómo se enfrentan a este contexto distinto a la escuela que ofrece el Túnel de la Ciencia? Así nació la idea de volver a ese lugar para realizar un pequeño estudio de campo.

Nuestra investigación implicó una inmersión en la realidad escolarizante que aqueja a muchos educadores y educandos (Escuelas y Colegios Tradicionales de 9 a 16 años). Esta exposición tiene un contexto ajeno a la escuela, pero ofrecía una buena oportunidad para poner en juego algunos "contenidos" y aprendizajes de los niños en temas como biología, física, historia, etc. Triste fue constatar que la interacción de los niños y adultos en el lugar evidenció su paupérrima realidad escolar. Se observó direccionalidad en la entrega de contenidos, jerarquización en las relaciones, monopolización de los profesores y monitores en los intercambios de información. Muy pocas veces se observó un momento en que los niños aportaron desde los "contenidos" que han aprendido, ya que en la escolarización de la información ligada al ámbito educativo tradicional está completamente normalizado y naturalizado que los niños no pregunten u objeten. El monitor, muchas veces se vio forzado a hacerlos participar, casi obligándolos a responder y a interactuar. La reacción de los niños frente a esto siempre fue temerosa, avergonzada, insegura, y casi siempre la respuesta fue incorrecta.

Asimismo, el aburrimiento y poca conexión que los escolares manifestaron con el entorno durante el recorrido dan cuenta de estos hechos: la exposición en sí, el conocimiento transmitido y la forma de aprendizaje no nacen de sus motivaciones personales, por lo tanto, una experiencia como esta, carece de un sentido y significado para ellos. Los niños que estaban más cerca del monitor se veían más atentos, no por ello más conectados o concentrados, sino que más bien se apreciaba cierta inercia irreflexiva ante una dinámica grupal cautiva que seguía a un líder, casi como un rebaño. Al tener la posibilidad de recorrer la exposición por su propia cuenta, daban vueltas sin sentido, sin 
interesarse por nada en particular, excepto unos pocos, alrededor de diez niños por delegación, una ínfima proporción considerando que los cursos siempre fueron de entre treinta a cuarenta y tantos alumnos. Los restantes conversaban entre ellos de diversas cosas de su interés, pero no de algo que tuviera que ver con la exposición.

Lo expuesto hasta acá es un claro reflejo de cómo los niños experimentan el proceso educativo en general. Siguiendo a Moreno (2016), la escuela actual se obsesiona por el control del tiempo, del espacio y del conocimiento entregado... lo cual no permite que el alumno fluya en el proceso de aprendizaje, ya que este fluir generará preguntas novedosas que obligará al profesorado a desviarse de esa línea causal que el control existente le obliga a mantener.

Lo observado deja en evidencia que aunque el aprendizaje es connatural al ser humano, si éste no está cargado de una significación que nazca de ellos mismos, de su necesidad real de aprender, solo lograremos un aparente interés mediante la coerción y el control por parte de la autoridad educativa o profesor. Será necesario entonces preguntarnos, ¿Debe remitirse el educador a ser este personaje de disciplina y control para ejercer su rol educativo? ¿Podrá la escuela concebirse como un espacio amoroso que se interesa realmente por la experiencia personal y la singularidad de cada niño y que dé lugar al asombro, antesala de los aprendizajes significativos?

Afortunadamente, y en oposición a lo anterior, pudimos observar una delegación de "Home Schoolers" (educación en casa). Estos niños tuvieron otra disposición frente a la exposición y su interacción fue completamente distinta a los demás grupos observados, de hecho bastante similar a cuando fuimos con los niños de nuestra Escuela, intervinieron constantemente de manera espontánea y con mucha confianza en ellos mismos desde los conocimientos y aprendizajes que tenían. Tuvieron un intercambio constante de información, estableciendo un diálogo permanente con el monitor en una interacción desjerarquizada. Sin embargo, nos llamó la atención que al finalizar la exposición, los niños recorrieron en calma los módulos con una aparente libertad, ya que fueron acompañados por los padres quienes parecieron asumir un cierto rol pedagógico, aunque deteniéndose en las cosas que les interesaban a los niños. 
Como conclusión de este ejercicio investigativo, se desprende la importancia de reflexionar sobre la experiencia del niño, vivida desde su propia naturaleza, como un ser que aprende, que no puede no aprender, considerando así este aspecto como central en su educación. Ya que cuando transita dicha experiencia desde su capacidad natural de asombro y curiosidad, desde un fluir de preguntas más que desde un mundo de respuestas, entonces nos encontraremos con un niño amoroso, feliz, seguro de sí mismo, desde la cooperación, la empatía y sus ganas infinitas de aprender.

\section{Referencias bibliográficas}

Moreno, A. (2016). Educación y Caos [del insípido orden escolar al sabroso desorden educativo]. Santiago. Ediciones de la Junji. 